\title{
Duodenal perforation due to toothpick perforation, an uncommon cause of chronic abdominal pain
}
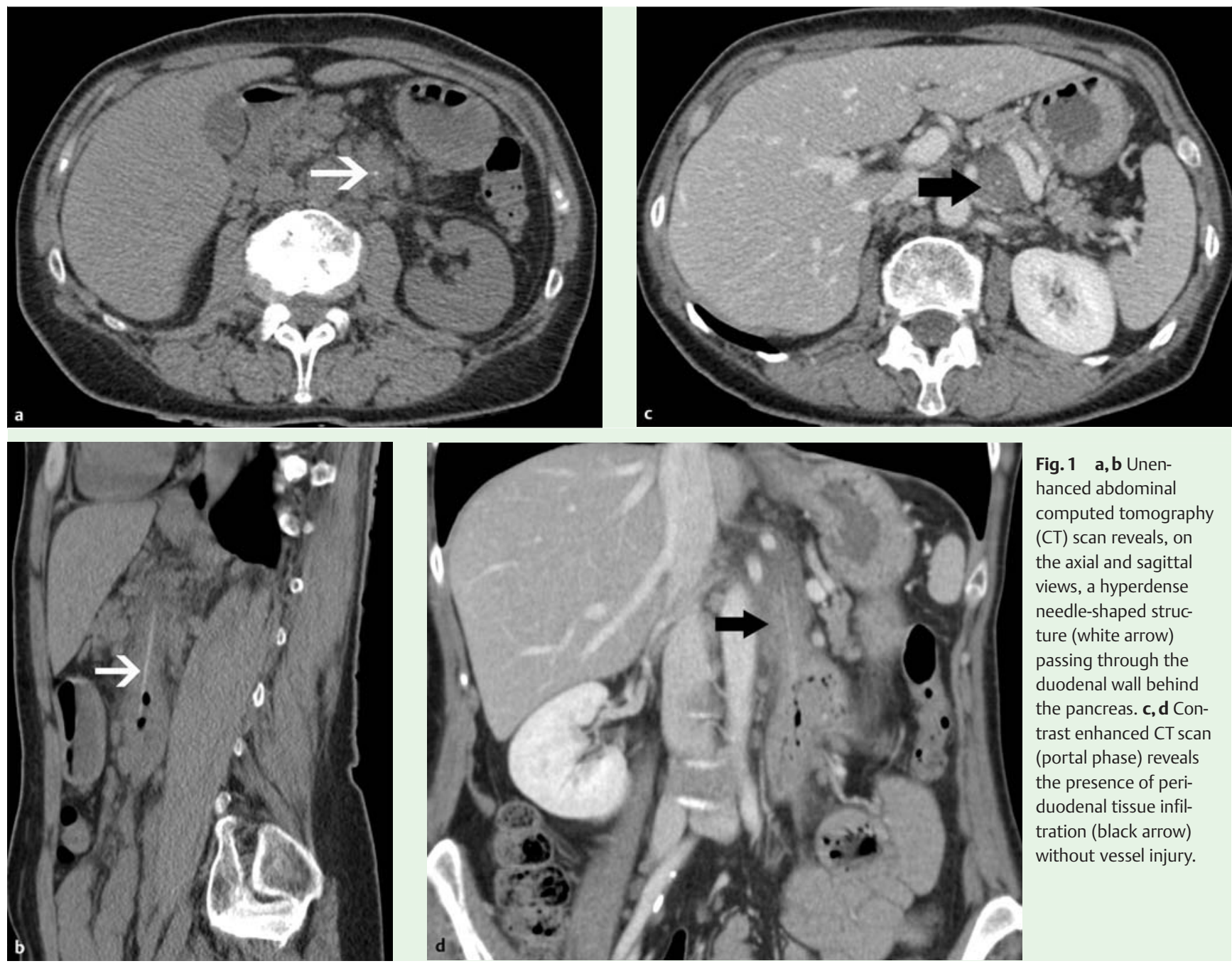

Fig. 1 a, b Unenhanced abdominal computed tomography (CT) scan reveals, on the axial and sagittal views, a hyperdense needle-shaped structure (white arrow) passing through the duodenal wall behind the pancreas. c, $\mathbf{d}$ Contrast enhanced CT scan (portal phase) reveals the presence of periduodenal tissue infiltration (black arrow) without vessel injury.

A 55-year-old woman presented with a 3month history of chronic left upper quadrant abdominal pain. She had no previous medical history. Her symptoms were not associated with nausea or emesis. Physical examination showed an afebrile patient with left upper quadrant abdominal tenderness. Laboratory tests demonstrated an elevated white cell count of $15000 / \mu \mathrm{L}$ (normal range $4000-10000 / \mu \mathrm{L}$ ). C reactive protein was $50 \mathrm{mg} / \mathrm{dL}$ (normal $<5 \mathrm{mg} / \mathrm{mL}$ ). Liver function tests were normal. Images from ultrasonography exploration were considered normal.

An abdominal computed tomography (CT) scan demonstrated an infiltration of periduodenal tissue above the angle of Treitz and a hyperdense needle-shaped structure penetrating the duodenal wall
(๑ Fig. 1). No vessel injury was seen. Upper gastrointestinal endoscopy revealed a wooden toothpick deeply embedded in the duodenal wall, and enabled it to be removed without the complications of bleeding or purulent flow ( Fig. 2). The patient was treated with a daily dose of proton pomp inhibitor and antibiotics for 7 days. She had no memory of ingesting the toothpick. The clinical course was uneventful. A follow-up CT scan confirmed regression of the periduodenal inflammation.

Most ingested foreign bodies pass through the intestinal tract without complication. Gastrointestinal bleeding or perforation are mostly observed with sharp objects like toothpicks. Other complications include peritonitis, abscess, obstruction, or perforation into adjacent organs. Toothpicks account for about $9 \%$ of ingested foreign bodies [1,2]. Risk factors for toothpick ingestion are mental pathology, alcohol abuse, rapid eating, and chewing of toothpicks [3]. Only $12 \%$ of patients remember eating a toothpick, therefore diagnosis of toothpick ingestion can be quite difficult. Most patients with intestinal perforation present with abdominal pain (70\%) or bleeding (7\%). Perforation occurs most frequently in the duodenal tract, probably related to an anatomical morphology with angulation and a $\mathrm{C}$ loop shape. The overall mortality rate is estimated at $18 \%$ [4].

In our case report, CT images were very useful to detect this foreign body, which appeared as a high density needle-shaped object. The CT scan made it possible to 


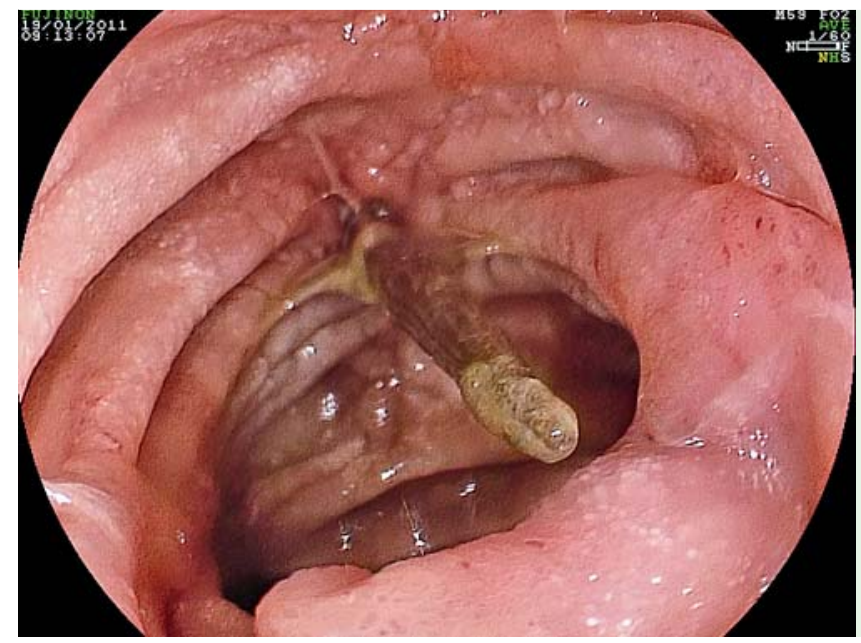

Fig. 2 Upper gastrointestinal endoscopy confirms an ingested toothpick embedded in the duodenal wall.

determine accurately the location of both ends of the toothpick. Moreover, the CT scan confirmed the depth of duodenal penetration and the absence of vessel injury before endoscopic removal of the toothpick. Upper gastrointestinal endoscopy is contraindicated when peritonitis or penetration of vessels is suspected. As previously described by other authors, toothpick ingestion can be a rare cause of chronic abdominal pain $[5,6]$. Endoscopic retrieval of this foreign body allows a proper recovery without complications, therefore endoscopy should be done as soon as possible to avoid complications. In conclusion, we report a case of duodenal perforation due to an ingested toothpick. Despite the option for endoscopic removal and short medical treatment which permits a favorable clinical course, toothpicks should be considered potentially dangerous.

Endoscopy_UCTN_Code_CCL_1AB_2AF

Competing interests: None

\section{B. Robert ${ }^{1}$, E. Bartoli ${ }^{2}$, M. Fumery ${ }^{2}$, M. Eoche ${ }^{2}$, C. Chivot ${ }^{1}$, F. Demasure ${ }^{3}$, H. Mancheron ${ }^{4}$, T. Yzet ${ }^{1}$}

${ }^{1}$ Department of Digestive Radiology, Amiens North Hospital, France

${ }^{2}$ Department of Gastroenterology and Hepatology, Amiens North Hospital, France

${ }^{3}$ Department of Radiology, Clinique de l'Europe, Amiens, France

${ }^{4}$ Department of Gastroenterology, Clinique de l'Europe, Amiens, France

\section{References}

1 Nigri GR, Di Giulio E, Di Nardo R et al. Duodenal perforation and right hydronephrosis due to toothpick ingestion. J Emerg Med 2008; 34: $55-57$

2 Matsubara M, Hirasaki S, Suzuki S. Gastric penetration by ingested toothpick successfully managed with computed tomography and endoscopy. Intern Med 2007; 46: 971 974

3 Steenvoorde P, Moues CM, Viersma JH. Gastric perforation due to ingestion of hollow toothpick: report of a case. Surg Today 2002; 32: 731-733

$4 \mathrm{Li}$ SF, Ender $\mathrm{K}$. Toothpick injury mimicking renal colic: case report and systematic review. J Emerg Med 2002; 23: 35-38

5 Grabysa R, Łowczak R, Kubiak M et al. Toothpick impaction in the sigmoid colon as a cause of chronic abdominal pain. Endoscopy 2010; 42: E203

6 Hsieh MJ, Lee TC, Tseng CH et al. Duodenumpenetrating toothpick with liver abscess: removal with single-balloon enteroscopy. Endoscopy 2011; 43: E11-E12

\section{Bibliography}

Dol http://dx.doi.org/

10.1055/s-0031-1291507

Endoscopy 2012; 44: E27-E28

(c) Georg Thieme Verlag KG

Stuttgart · New York

ISSN 0013-726X

Corresponding author:

\section{B. Robert, MD}

Department of Digestive Radiology

Amiens North Hospital

University of Picardy

Place Victor Pauchet

80054 Amiens Cedex 01

France

Fax: +33-3-22668628

robert.brice@chu-amiens.fr 